\title{
DISRUPTED NETWORKS
}

From Physics to Climate Change 


\section{STUDIES OF NONLINEAR PHENOMENA IN LIFE SCIENCE}

Editor-in-Charge: Bruce J. West

Vol. 1 Fractal Physiology and Chaos in Medicine by $B$ J West

Vol. 2 Patterns, Information and Chaos in Neuronal Systems edited by $B J$ West

Vol. 3 The Lure of Modern Science - Fractal Thinking by $B J$ West \& $B$ Deering

Vol. 4 Physical Theory in Biology - Foundations and Explorations edited by C J Lumsden, W A Brandts \& LE H Trainor

Vol. 5 Nonlinear Dynamics in Human Behavior edited by $W$ Sulis \& A Combs

Vol. 6 The Complex Matters of the Mind edited by F Orsucci

Vol. 7 Physiology, Promiscuity, and Prophecy at the Millennium: A Tale of Tails by $B J$ West

Vol. 8 Dynamics, Synergetics, Autonomous Agents: Nonlinear Systems Approaches to Cognitive Psychology and Cognitive Science edited by W Tschacher \& J-P Dauwalder

Vol. 9 Changing Mind: Transitions in Natural and Artificial Environments by F F Orsucci

Vol. 10 The Dynamical Systems Approach to Cognition: Concepts and Empirical Paradigms based on Self-Organization, Embodiment, and Coordination Dynamics edited by W Tschacher \& J-P Dauwalder

Vol. 11 Where Medicine Went Wrong: Rediscovering the Path to Complexity by $B$ J West

Vol. 12 Mind Force: On Human Attractions by F Orsucci

Vol. 13 Disrupted Networks: From Physics to Climate Change by $B$ J West \& N Scafetta 


\section{DISRUPTED NETWORKS From Physics to Climate Change}

\section{Bruce J. West \& Nicola Scafetta}

Duke University, USA 


\section{Published by}

World Scientific Publishing Co. Pte. Ltd.

5 Toh Tuck Link, Singapore 596224

USA office: 27 Warren Street, Suite 401-402, Hackensack, NJ 07601

UK office: 57 Shelton Street, Covent Garden, London WC2H 9HE

\section{British Library Cataloguing-in-Publication Data}

A catalogue record for this book is available from the British Library.

\section{Studies of Nonlinear Phenomena in Life Science - Vol. 13 DISRUPTED NETWORKS \\ From Physics to Climate Change}

Copyright (c) 2010 by World Scientific Publishing Co. Pte. Ltd.

All rights reserved. This book, or parts thereof, may not be reproduced in any form or by any means, electronic or mechanical, including photocopying, recording or any information storage and retrieval system now known or to be invented, without written permission from the Publisher.

For photocopying of material in this volume, please pay a copying fee through the Copyright Clearance Center, Inc., 222 Rosewood Drive, Danvers, MA 01923, USA. In this case permission to photocopy is not required from the publisher.

ISBN-13 978-981-4304-30-6

ISBN-10 981-4304-30-1

Printed in Singapore. 


\section{Preface}

This is a book about complexity, complex networks and how their smooth dynamics is often disrupted. But before we can proceed it would appear that we should answer the question: "What is complexity?" Over the past two decades both professional scientists and lay people alike have wondered about the scientific meaning of this simple yet elusive word. In the fourth century St. Augustine asked himself a related odd question: "What is time?" His answer was astonishingly interesting:

What, then, is time? If no one asks me, I know what it is. If I wish to explain it to him who asks me, I do not know.

A similar answer can be reformulated about the concept of complexity. OK, let us see how it sounds: "What, then, is complexity? If no one asks me, I know what it is. If I wish to explain it to him who asks me, I do not know." But science does not wait for definitions, science continues forward in its investigations of a phenomenon with or without clear understanding, confident that such understanding will eventually come.

As with the concept of time, the concept of complexity cannot be explained or defined in a simple way. It is easier to appeal to intuition, that is, to that mysterious faculty that allows humans to visualize the meaning of a difficult concept without confining it to a definition. Thus, we decided in writing this book that an interesting way to stimulate the intuition of our readers about the nature of complexity and complex networks is to give a concise overview of how the scientific, technological and sociological facts that emerged since the end of the twentieth century have engendered the need to address a significant portion of what is viewed as science from a new perspective. This new perspective does not rely on any particular discipline for its articulation and is known as the science of complexity. Our interest, in particular, is in its special form as the science of complex networks. 
We found the approach of viewing the changes in sciences from above to be quite interesting and stimulating and hope you do as well. We realized in writing that it might be possible to describe what complexity is, and what complex networks are, using a language that can certainly attract the attention of a wide range of non-professionals. Adopting an appropriate didactic approach to explain complex networks is not, however, just an attempt to reach people who are not familiar with the language of science. Indeed, finding a way to communicate effectively with most educated people inside and outside the scientific community is a necessity given society's reliance on science and technology. Such a language might also entice professional scientists from a multitude of different fields, such as neurophysiologists, biologists, sociologists, meteorologists, chemists and, of course, physicists to work together on problems of importance to society.

The image of the renaissance person, the universal scientist such a Leonardo da Vinci who was able to master all the known science of his day, has faded from the possible. This loss over the last century is due to the development of a new kind of science that requires ever increasing specialization. This need to specialize birthed scientists so deeply compartmentalized that they isolated themselves from each other, and by doing so they isolated their fields of research as well. Mathematics, physics, biology, geology, astronomy, sociology, economics, medicine and even their sub-disciplines are now believed to be intrinsically separate domains of knowledge. As for a way to communicate, isolation yielded to differentiation, and what were just small dialectical variants at the beginning, in a few scientific generations evolved into specialized languages that have made each field of research foreign to all but the expert.

However some scientists realized that specialization in just one field of research was not always beneficial, and could, in fact, be a fatal limitation on knowledge. Understanding complex networks requires knowledge that does not reside within a single discipline and, because of the extreme richness of the current level of science, requires collaboration across disciplines. In his book Cybernetics, the mathematician Norbert Wiener observes:

...a proper exploration of these blank spaces on the map of science could only be made by a team of scientists, each a specialist in his own field but each possessing a thoroughly sound and trained acquaintance with the fields of his neighbors; all in the habit of working together, of knowing one another's intellectual customs, 
and of recognizing the significance of a colleague's new suggestion before it has taken on a full formal expression.

Multidisciplinary collaboration requires a common language: a kind of lingua franca. The only lingua franca that is available is the non-technical language of ordinary speech. Thus, one problem scientists face is how to use a non-specialized language to communicate and introduce the progress made by scientists in different fields on the understanding of complexity and complex networks. It is the notion, role and function of scientists that is continuing to change in a rapid manner; that being not only investigator, but communicator as well. The necessity for better communication within science and between science and society is forcing new ways to illustrate scientific progress.

Thus, we organized our book in such a way as to bring the reader along on a wonderful trip through the emergence, growth and expansion of modern science, the Science of Complex Networks. We guide you through several examples from different areas of complexity, rather than providing a chronological review of what has been done. Because of this diversity the exemplars may appear disconnected. But with each stop on the junket, we believe that you will see more and more clearly how the apparently disconnected stories and findings are intrinsically linked by a novel underlying scientific methodology.

You will be able to recognize that a systematic investigation of complex networks has emerged as a new kind of science; based on a new scientific methodology. What will become evident is an irreducible difference between the dialectical two-tiered structure of the traditional scientific methodology (experiment and theory) and the new methodology, which naturally emerges in the study of complex networks that entails three tiers: experiment, computational simulation and theory. This new methodology can be transcribed into data, information and knowledge.

The historically two-tiered science is how the scientific method is usually presented and understood. The data resulting from observation/experiment suggest a theoretical model that not only explains the data but also enables prediction. Such predictions are tested by doing new experiments and/or making new observations that lead to improved theoretical models. This dialectic process between successive improvements on experiments and theory leads to an iteratively progressive understanding of a given phenomenon. Until recently all major fields of science developed by following this two-tiered 
science methodology. The two-tiered science allowed us to discover fundamental laws of physics and show how the vanishingly small and the astronomically large are part of the same unity. However, what is most interesting is the realization that this methodology, which facilitated the development of science from the time of Newton, works only if the theoretical predictions can be directly tested against the observations. This obvious constraint is relatively easy to satisfy only if the network under study is simple. Thus, the historical methodology necessitates isolating or disentangling elements from the whole and it is the ability to disentangle that makes the phenomenon simple.

However, typical complex networks, such as those found in biology, geophysics, sociology and economics, cannot be disentangled into elementary components to be studied separately. What makes a complex network complex is the fact that it is an entangled organism. It is the structure of these networks that characterize them, altering the topology of complex networks changes them in a disruptive way. Cutting the heart out of a dog to better study how it works may not be satisfactory because, after all, the result is a dysfunctional organ and a dead dog! Even if the heart is kept alive artificially the dog is still dead. Thus, studying complex networks requires a middle ground to fill the gap between, say the theoretical understanding of fundamental physics and the often poorly resolved experimental observations of biology. This filling-in is done with complex calculations and computer simulations that have been made possible by the increasing availability of computers and the enhanced complexity of computer algorithms over the last few decades. It is this computational complexity that constitutes the third level of the new scientific methodology that is required for studying complex networks.

Three-tiered science is a new methodology because the dialectic form of the traditional two-tiered scientific method is disrupted by the alternatives presented by this additional level of investigation. The viability of the third tier has been continually tested by scientists over the last half century. Theory and experiment can no longer be directly compared in many studies because the phenomena are too complex, and computational complexity does not establish the uniqueness of such a comparison. Different alternative models can be opportunely tuned or adjusted to make them fit the data, but it is not possible to start from first principles and determine which model is the better representation of reality. Significant analyses of the data is required to determine which model is preferable and sometimes these data 
processing efforts are frustrated by the low quality of the data. Consequently, competitive theories (models) are not really tested against each other with the kind of certainty that has historically characterized such comparisons in theoretical physics.

We decided to illustrate the procedures involved in analyzing existing complex networks by discussing the debate on climate change. Few networked phenomena are more complex than the Earth's climate. Even fewer networked phenomena generate issues that are more intriguing than that of climate change and global warming where the tree-tired science of data, computer simulations and theoretical knowledge is so well exposed with all its benefit and difficulties. This debate is not an arcane academic exercise but is an important issue of general interest to most industrialized societies that are concerned about the future of our planet. The example of climate change is also a useful illustration of the influence of society on science, in terms of what research is supported, as well as, the influence of science on society in terms of what phenomena are thought to be important. Consequently, the climate change example, which is extremely important in itself, herein becomes a paradigm of a disrupted complex network exposing the strengths and weaknesses of this nascent science.

This book highlights a number of features concerning how science really works and not necessarily how we would like it to work. Complex networks, complexity, commonality, interdisciplinarity, transdisciplinarity, etc., are all important new ways of looking at the world. Network science is presented as a new kind of epistemology, or way of knowing the world; not just the world of physical science, but the world of biological, economic, social, and life sciences as well. We hope that our discussion will assist lay readers in understanding how the young field of complex networks is evolving and will provide the professionals in many different areas of research a perspective by which to appreciate the interconnectedness among all disciplines. This book results from the efforts of two physicists with multiple interests and is not a substitute for a textbook, but it may supplement such texts with a pleasurable and educational read. Hopefully it will bridge the gaps among a variety of disciplines that the three-tiered science of our times entails.

Bruce J. West

Nicola Scafetta

Physics Department

Duke University, Durham NC 
This page intentionally left blank 


\section{Contents}

Preface $\quad$ v

1 Why a Science of Networks? 1

1.1 The science of data, information and knowledge . . . . . . . 4

1.2 The face of science . . . . . . . . . . . . . . . . 11

1.2.1 Qualitative and quantitative ........... 17

1.2.2 What is a complex network? . . . . . . . . . . 24

1.2.3 A taxonomy of complex networks . . . . . . . . . . 27

1.2.4 The three-tiers of science . . . . . . . . . . . . . 34

1.3 Framing the climate change debate . . . . . . . . . . . . 40

1.3.1 The Intergovernmental Panel on Climate Change . . . 43

1.3.2 Climate topologies in comparison . . . . . . . . . . 51

2 Data $\quad 69$

2.1 Physics as a scientific paradigm . . . . . . . . . . . 72

2.1.1 Psychophysics quantifies individuals . . . . . . . . . 78

2.1.2 Sociophysics quantifies groups . . . . . . . . . . . . . 83

2.1.3 Econophysics quantifies exchange . . . . . . . . . . . 89

2.1.4 Biophysics quantifies life . . . . . . . . . . . . . . . 94

2.2 Time series . . . . . . . . . . . . . . . . . . . 96

2.2 .1 Measures and data . . . . . . . . . . . . . . . . 97

2.2.2 Representing the data . . . . . . . . . . . . . . . . . . . . . . . . . . . . . . . . .

2.3 Fractal statistics . . . . . . . . . . . . . . . . 105

2.4 Solar and climate variability . . . . . . . . . . . . . . . 112

2.4.1 Solar data . . . . . . . . . . . . . . . . . 115

2.4.2 Temperature data . . . . . . . . . . . . . . 125 
3 Information 135

3.1 Entropy . . . . . . . . . . . . . . . . . . . . . 138

3.1.1 Wiener-Shannon Information . . . . . . . . . . . . 143

3.1.2 The Physicality of Information . . . . . . . . . . . . . 146

3.2 Pareto's Law . . . . . . . . . . . . . . . . . . . 151

3.2.1 Economic networks . . . . . . . . . . . . . 157

3.2 .2 Science networks . . . . . . . . . . . . . . . . . 162

3.2 .3 Information networks . . . . . . . . . . . . . . . 170

3.2.4 Social-communication networks . . . . . . . . . . 172

3.2.5 Networks of neurons . . . . . . . . . . . . . . . . . . . 179

3.3 Entropy and data processing . . . . . . . . . . . . . . 180

3.3.1 Diffusion of Information . . . . . . . . . . . . . . . 182

3.3.2 Diffusion entropy analysis . . . . . . . . . . . . . . 188

3.4 Sun-climate complexity matching? . . . . . . . . . . . . . . 194

4 Knowledge 197

4.1 Mathematics enables knowledge . . . . . . . . . . . 200

4.2 The Pareto Principle: the $80 / 20$ rule . . . . . . . . . . . . . . 203

4.3 What we know about complex networks . . . . . . . . 206

4.3.1 Random networks . . . . . . . . . . . . . . . . . 211

4.3.2 Scale-free networks and the STDs epidemic . . . . . . . 215

4.3.3 Scale-rich networks . . . . . . . . . . . . . . . . 222

4.4 The Sun-climate linking: an ongoing debate . . . . . . . . . 226

4.4.1 The Hockey Stick graph and the climate models . . . . 228

4.4.2 The 11-year solar cycle signature on climate: models vs. data . . . . . . . . . . . . . . . . . 237

4.4.3 The phenomenological reconstruction of the solar signature on climate . . . . . . . . . . . . . . 244

5 A World of Disrupted Networks 253

Glossary

$\begin{array}{ll}\text { Bibliography } & 271\end{array}$

$\begin{array}{ll}\text { Index } & 289\end{array}$ 